\title{
Effects of Aloe Vera and Swimming Training on Lipid Profile of Streptozotocin Induced Diabetic Rats
}

\author{
Seyed Ali Hosseini* ${ }^{1}$, Fariba Khoshsovt ${ }^{2}$, Mozhgan Ahmadi ${ }^{3}$, Mohammad Ali Azarbayjani ${ }^{4}$, Omidreza Salehi ${ }^{5}$, Fatemeh Farkhaie ${ }^{2}$ \\ 1- Associated Professor, Department of Sport Physiology, Marvdasht Branch, Islamic Azad University, Marvdasht, Iran. \\ 2- MSc, Department of Sport Physiology, Marvdasht Branch, Islamic Azad University, Marvdasht, Iran. \\ 3- Assistant Professor, Department of Physical Education and Sport Science, Yadegar-e-Imam Khomeini (RAH) Shahre-rey Branch, Islamic Azad \\ University, Tehran, Iran. \\ 4- Professor, Department of Sport Physiology, Central Tehran Branch, Islamic Azad University, Tehran, Iran. \\ 5- PhD student, Department of Physical Education and Sport Sciences, University of Kurdistan, Sanandaj, Iran
}

\section{A B S T R A C T}

Background and Objectives: Exercise and nutrition are two effective factors in controlling diabetes-induced metabolic disorders. The aim of this study was to assess effects of aloe vera and swimming training on lipid profile of the diabetic rats.

Materials and Methods: In this experimental study, 72 diabetic rats were selected and divided into nine groups of eight rats, including 1) four weeks of aloe vera consumption (FAV), 2) six weeks of aloe vera consumption (SAV), 3) four weeks of swimming (FS), 4) six weeks of swimming (SS), 5) four weeks of aloe vera consumption with swimming (FAVS), 6) six weeks of aloe vera consumption with swimming (SAVS), 7) Week-1 diabetic control (DC), 8) Week-4 diabetic control (FDC), and 9) Week-6 diabetic control (SDC). Groups 1, 2, 5 and 6 received $100 \mathrm{mg} \mathrm{kg}^{-1}$ of aloe vera daily. Furthermore, Groups 3 and 5 swam for four weeks and Groups 4 and 6 for six weeks, five sessions per week and 30 minutes each session. Data were analyzed using one-way ANOVA, two-way ANOVA and Bonferroni post-hoc tests $(P \leq 0.05)$.

Results: Results showed that training, aloe vera and aloe vera with training significantly decreased levels of triglyceride (TG), total cholesterol (TC), low density lipoprotein (LDL) and very low density lipoprotein (VLDL) $(P \leq 0.05)$; four and six weeks of swimming trainings decreased TG, TC, LDL and VLDL $(P \leq 0.05)$; and six weeks of aloe vera consumption decreased TG, TC, LDL and VLDL $(P \leq 0.05)$.

Conclusions: Four and six weeks of aloe vera consumption and swimming training include interactive lipid lowering effects in streptozotocin induced diabetic rats.

Keywords: Training, Aloe vera, Diabetes, Lipid profile

\section{Introduction}

Diabetes mellitus is one of the most important endocrine disorders and one of the the most common health problems worldwide (1). Diabetes mellitus is a metabolic disorder that interferes with glucose metabolism and negatively affects metabolisms of lipids and proteins. Diabetes is either due to insulin deficiency (type-1 diabetes) or due to tissue resistance to insulin (type-2 diabetes). This disorder is associated with an increased risk of premature cardiovascular diseases (CVD). In diabetic patients, risk of CVDs is $4-5$ times greater than non-diabetic patients (3). Lipid dysfunctions such as increased levels of total cholesterol (TC), low-density lipoprotein cholesterol (LDL), triglycerides (TG) and decreased high-density lipoprotein cholesterol (HDL) are important risk factors for diabetics; therefore, monitoring lipid disorders in these patients is important (4). Use of medicinal plants in traditional medicine of Asian nations such as China, India and Iran includes a history of several thousand years (5). 
One of these plants, aloe vera, has widely been used in medicine of several countries for thousands of years. In recent years, clinical studies have been carried out on therapeutic effects of this plant. In addition to its use in health and beauty products, aloe vera includes multiple therapeutic properties such as antioxidant, anticancer, anti-inflammatory, laxative and anti-atherosclerosis properties. In addition, it contains 75 active ingredients, including vitamins, enzymes, minerals, carbohydrates, lignin, salicylic acids and amino acids $(6,7)$. In a study, 21 days of oral use of aloe vera leaf alcoholic extract improved the metabolism of glycoproteins in animal models of diabetes (8). Evidence are available on carbohydrate metabolism regulating effects of this plant. Moreover, beneficial effects of aloe vera have been reported in decrease of damages in liver tissues of diabetic rats (6) and oxidative damages in hippocampus and brain cortex of type-2 diabetic rats (7). Studies have shown that use of aloe vera in diabetics includes the potential of lowering lipid and glucose levels (9, 10). Moreover, effects of physical activity on lipid and lipoprotein levels have been considered in several studies (11). For many years, exercise has been used as a supplement to drug treatment in diabetes management. Studies in humans and animals have shown that exercise improves insulin resistance and increases insulin sensitivity (1). However, there is a little information on the effects of exercise on lipid profiles in diabetes. As previously stated, results of studies have indicated that increased physical activities improve lipid profiles in diabetic patients. In addition, studies have been carried out on the effects of aloe vera on lipid concentration. However, combined effects of various sport exercises and aloe vera extracts on lipid profiles of diabetics have not been studied. Therefore, effects of four and six weeks of swimming training in combination with aloe vera consumption on lipid profile of diabetic male rats were investigated in the current study.

\section{Materials and Methods}

\section{Animals}

In this experimental study, 96 Sprague-Dawley adult male rats aged eight weeks and weighed 262.83 $\mathrm{g} \pm 47.59$ were purchased from the Animal House of Islamic Azad University, Marvdasht, Iran, and transferred to Sport Physiology Laboratory of the university. The study was approved by the Research
Ethics Committee of the university. For the adaption of animals to the laboratory environment, rats were hosted in the laboratory for one week. During this time and throughout the whole study, rats had free access to food and water. After one week of adaptation, 72 rats were injected peritoneally with 60 $\mathrm{mg} \mathrm{kg}{ }^{-1}$ of streptozotocin (Sigma, Germany). After four days and following a fasting night, fasting glucose of the rats was assessed by punching the rat tails using glucometer (01-Mini, Japan). Rats with fasting glucose up to $300 \mathrm{mg} \mathrm{dl}^{-1}$ were selected as statistical samples. Considering fasting glucose, these animals were randomly divided into nine groups of eight animals, including 1) four weeks of aloe vera consumption (FAV); 2) six weeks of aloe vera consumption (SAV); 3) four weeks of swimming training (FS); (4) six weeks of swimming training (SS); 5) four weeks of aloe vera consumption with swimming training (FAVS); 6) six weeks of aloe vera consumption with swimming training (SAVS); 7) Week-1 diabetic control (DC); 8) Week-4 diabetic control (FDC); and 9) Week-6 diabetic control (SDC). To study effects of diabetes induction on the lipid profile of rats, 24 healthy rats were divided into three groups of eight rats, including 1) Week-1 healthy control; 2) Week-4 healthy control; and 3) Week-6 healthy control. The study groups were hosted in rodent special cages made of PVC with steel mesh caps and wood-chip covered floors. Room temperature was $22 \pm 1.4{ }^{\circ} \mathrm{C}$ with $45 \%$ humidity. Experimental animals included a 12-h sleeping/awakening cycle with free access to water and food. Rats in Groups 3 and 5 and rats in Groups 4 and 6 swam in a special swimming tank with dimensions $100 \times 50 \times 50 \mathrm{~cm}$ for four and six weeks respectively; five sessions per week each session of 30 min. Furthermore, rats in Groups 1, 2 and 5 were peritoneally injected with $100 \mathrm{mg} \mathrm{kg}^{-1}$ doses of aloe vera extracts every day (12). The control groups did not have exercise activities during the study.

\section{Preparation of aloe vera extracts}

To prepare aloe vera extracts, fresh leaves were first washed and cut and then gels in the leaves were removed. These were centrifuged at $4000 \times$ rpm for 15 min to separate fibers. Solutions were extracted after drying with 95\% ethanol. After removing ethanol using rotary device, extracts were dissolved in normal saline and injected peritoneally into the rats (13). In the present study, the active ingredient of the aloe 
vera hydroalcoholic extracts included aloevine (14.9 mg per $100 \mathrm{~g}$ of gel).

\section{Exercise protocol}

The swimming training protocol included four and six weeks of swimming in water at $25-30{ }^{\circ} \mathrm{C}$ for 30 min per session, five sessions per week. After each training session, rats were dried using hair dryer. Training overload was reported by adjusting the strength and speed of the water during the swimming, which was consistent with the training during the week (14).

\section{Sampling procedures and measuring changes}

Briefly, $24 \mathrm{~h}$ after the last training session, rats were anesthetized using intraperitoneal injections of ketamine $\left[90 \mathrm{mg} \mathrm{kg}^{-1}\right]$ and xylazine $\left[10 \mathrm{mg} \mathrm{kg}^{-1}\right]$ and then blood samples were collected. Samples were immediately frozen in liquid nitrogen $\left(-196{ }^{\circ} \mathrm{C}\right)$ and stored at $-80{ }^{\circ} \mathrm{C}$ until use. Assessments of TG, TC and HDL were carried out enzymatically using commercial biochemical kits (Yasa Teb Medicine, Iran). Moreover, LDL was assessed using Friedewald equation and VLDL was calculated by dividing TG by five (15).

\section{Statistical method}

In the present study, Kolmogorov-Smirnov test was used for testing normality of data and one-way NOVA for reviewing effects of diabetes induction on research variables. In this study, two-way ANOVA was used at $P \leq 0.05$. All statistical analyses were carried out using SPSS Software v.23 (IBM Analytics, USA).

\section{Results}

The lipid profiles of rats are presented in Table 1.

Results of one-way ANOVA showed significant differences in levels of TG $(\mathrm{F}=16.44, P=0.001)$, TC $(\mathrm{F}=5.08, P=0.001)$, VLDL $(\mathrm{F}=16.44, P=0.001)$ and LDL $(\mathrm{F}=3.18, P=0.01)$ in healthy control and diabetic control groups. However, no significant differences were seen in HDL levels in healthy control and diabetic control groups $(\mathrm{F}=1.54, P=0.19)$. Results of Bonferroni post-hoc test for the comparison of lipid profiles of rats in healthy control group of Week 1 with diabetic control group of Week 1 showed that induction of diabetes with streptozotocin included significant effects on increased TG and VLDL $(P \leq 0.05)$. However, no significant effects were observed on TC, HDL and LDL changes in rats $(P \geq 0.05)$. Results of Bonferroni post-hoc test for the comparison of lipid profiles of rats in healthy control groups of Weeks 1, 4 and 6 showed that Weeks 4 and 6 included no significant effects on changes in TG, TC, HDL, VLDL and LDL $(P \geq 0.05)$. Furthermore, results of this test for the comparison of lipid profiles of rats in diabetic control groups of Weeks 1, 4 and 6 showed that Weeks 4 and 6 included no significant effects on changes in TG, TC, HDL, VLDL and LDL $(P \geq 0.05)$.

Table 1. Lipid profile levels of the 12 rat groups in this study

\begin{tabular}{|c|c|c|c|c|c|c|}
\hline Group & Variable & $\begin{array}{c}\mathrm{TG} \\
(\mathrm{mg} / \mathrm{dl})\end{array}$ & $\begin{array}{c}\mathrm{TC} \\
(\mathrm{mg} / \mathrm{dl})\end{array}$ & $\begin{array}{l}\text { HDL } \\
(\mathrm{mg} / \mathrm{dl})\end{array}$ & VLDL mg/dl) & $\begin{array}{l}\mathrm{LDL} \\
(\mathrm{mg} / \mathrm{dl})\end{array}$ \\
\hline \multirow{3}{*}{ Healthy } & First week control & $178.62 \pm 30.45$ & $183.87 \pm 61.00$ & $31.25 \pm 2.76$ & $35.72 \pm 6.09$ & $179.40 \pm 56.82$ \\
\hline & Fourth week control & $211.87 \pm 37.28$ & $193.25 \pm 29.18$ & $34.87 \pm 4.08$ & $42.37 \pm 7.45$ & $185.75 \pm 23.01$ \\
\hline & Sixth week control & $180.37 \pm 29.01$ & $160.75 \pm 25.38$ & $31.72 \pm 3.41$ & $36.07 \pm 5.80$ & $156.42 \pm 21.05$ \\
\hline \multirow{9}{*}{ Diabetic } & First week control & $270.50 \pm 38.50$ & $236.00 \pm 41.04$ & $33.62 \pm 4.50$ & $54.10 \pm 7.70$ & $215.52 \pm 40.90$ \\
\hline & Fourth week control & $264.25 \pm 44.18$ & $236.00 \pm 35.17$ & $30.75 \pm 3.05$ & $52.85 \pm 8.83$ & $213.90 \pm 27.53$ \\
\hline & Sixth week control & $290.75 \pm 18.65$ & $231.75 \pm 40.03$ & $33.00 \pm 3.33$ & $58.15 \pm 3.73$ & $206.60 \pm 39.11$ \\
\hline & Four weeks swimming & $123.28 \pm 7.99$ & $109.28 \pm 8.82$ & $39.71 \pm 2.87$ & $24.65 \pm 1.59$ & $124.34 \pm 7.69$ \\
\hline & Six weeks swimming & $134.57 \pm 47.54$ & $112.57 \pm 26.25$ & $30.00 \pm 6.02$ & $26.91 \pm 9.50$ & $115.65 \pm 22.67$ \\
\hline & $\begin{array}{l}\text { Four weeks Aloe Vera } \\
\text { consumption }\end{array}$ & $257.16 \pm 26.93$ & $251.16 \pm 31.69$ & $39.00 \pm 0.89$ & $51.43 \pm 5.38$ & $238.73 \pm 30.44$ \\
\hline & $\begin{array}{l}\text { Six weeks Aloe Vera } \\
\text { consumption }\end{array}$ & $151.33 \pm 57.23$ & $96.66 \pm 14.48$ & $34.00 \pm 2.75$ & $30.26 \pm 11.44$ & $100.40 \pm 5.99$ \\
\hline & $\begin{array}{l}\text { Four weeks Aloe Vera } \\
\text { consumption with swimming }\end{array}$ & $91.83 \pm 12.65$ & $79.66 \pm 11.21$ & $43.83 \pm 3.06$ & $18.36 \pm 2.53$ & $105.13 \pm 7.06$ \\
\hline & $\begin{array}{l}\text { Six weeks Aloe Vera } \\
\text { consumption with swimming }\end{array}$ & $75.50 \pm 6.18$ & $65.33 \pm 12.58$ & $31.66 \pm 12.30$ & $15.10 \pm 1.23$ & $81.90 \pm 20.04$ \\
\hline
\end{tabular}


Results of two-way analysis of variance showed that swimming training $(\mathrm{F}=110.82, P=0.001$, effect size $=0.85)$ and use of aloe vera extract $(\mathrm{F}=37.63$, $P=0.001$, effect size $=0.65$ ) significant affected TG decrease in diabetic rats. Moreover, swimming training with aloe vera consumption interactive affected TG decrease in diabetic rats $(\mathrm{F}=5.79$, $\mathrm{P}=0.006$, effect size $=0.22$ ). Results of Bonferroni post-hoc test demonstrated that four and six weeks of swimming training included significant effects on TG decrease in diabetic rats $(P \leq 0.05)$. However, four and six weeks of swimming training and use of aloe vera extract for six weeks included similar effects on TG decrease in diabetic rats $(P \leq 0.05)$. However, use of aloe vera extract for four weeks did not significantly affect TG decrease in diabetic rats $(P \geq 0.05)$ (Fig. 1).
Swimming training $(\mathrm{F}=118.98, P=0.001$, effect siz $=0.85)$ and aloe vera consumption $(\mathrm{F}=65.73$, $P=0.001$, effect size $=0.77$ ) included significant effects on TC decrease in diabetic rats. Swimming training with aloe vera consumption included interactive effects on TC decrease in diabetic rats $(\mathrm{F}=17.32$, $P=0.001$, effect size $=0.47$ ). Results of Bonferroni post-hoc test showed that four and six weeks of swimming training significantly affected TC decrease in diabetic rats $(P \leq 0.05)$. However, four and six weeks of swimming training similarly affected TC decrease in diabetic rats $(P \geq 0.05)$. Furthermore, use of aloe vera extract for six weeks included significant effects on TC decrease in diabetic rats $(P \leq 0.05)$. However, use of aloe vera extract for four weeks did not include significant effects on TC decrease in diabetic rats $(P \geq 0.05)$ (Fig. 2$)$.

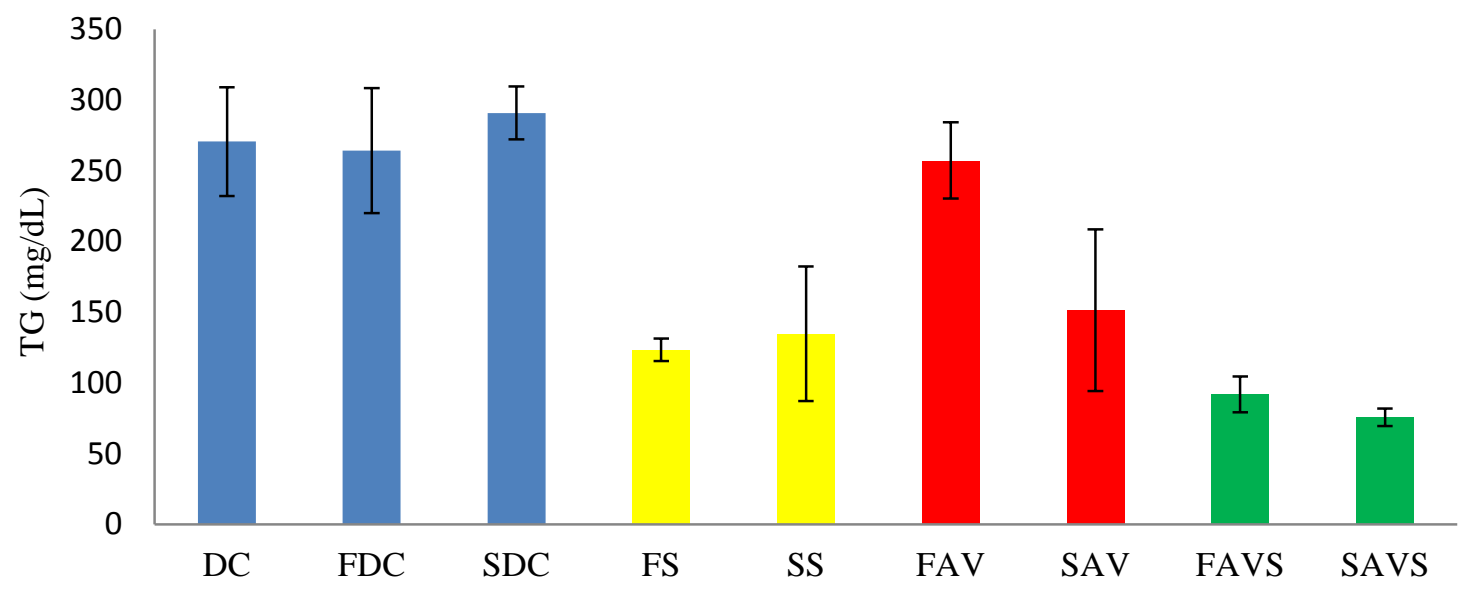

Figure 1. Triglyceride levels in diabetic groups of rats. FAV, four weeks of aloe vera consumption; SAV, six weeks of aloe vera consumption; FS, four weeks of swimming; SS, six weeks of swimming; FAVS, four weeks of aloe vera consumption with swimming training; SAVS, six weeks of aloe vera consumption with swimming training; DC, Week-1 diabetic control; FDC, Week-4 diabetic control; and SDC, Week-6 diabetic control



Figure 2. Cholesterol levels in diabetic groups of rats. FAV, four weeks of aloe vera consumption; SAV, six weeks of aloe vera consumption; FS, four weeks of swimming; SS, six weeks of swimming; FAVS, four weeks of aloe vera consumption with swimming training; SAVS, six weeks of aloe vera consumption with swimming training; DC, Week-1 diabetic control; FDC, Week-4 diabetic control; and SDC, Week-6 diabetic control 
Swimming training $(\mathrm{F}=110.82, P=0.001$, effect size $=0.85)$ and use of aloe vera extract $(\mathrm{F}=37.63$, $P=0.001$, effect size $=0.65$ ) significantly affected VLDL decrease in diabetic rats. Swimming training with use of aloe vera extract interactively affected VLDL decrease in diabetic rats $(\mathrm{F}=5.79, P=0.006$, effect size $=0.22$ ). Results of Bonferroni post-hoc test showed that four and six weeks of swimming training included significant effects on VLDL decrease in diabetic rats $(P \leq 0.05)$; however, four and six weeks of swimming training included similar effects on VLDL decrease in diabetic rats $(P \geq 0.05)$. Furthermore, use of aloe vera extract for six weeks included significant effects on VLDL decrease in diabetic rats $(P \leq 0.05)$. However, use of aloe vera extract for four weeks did not include significant effects on VLDL decrease in diabetic rats $(P \geq 0.05)$ (Fig. 3).

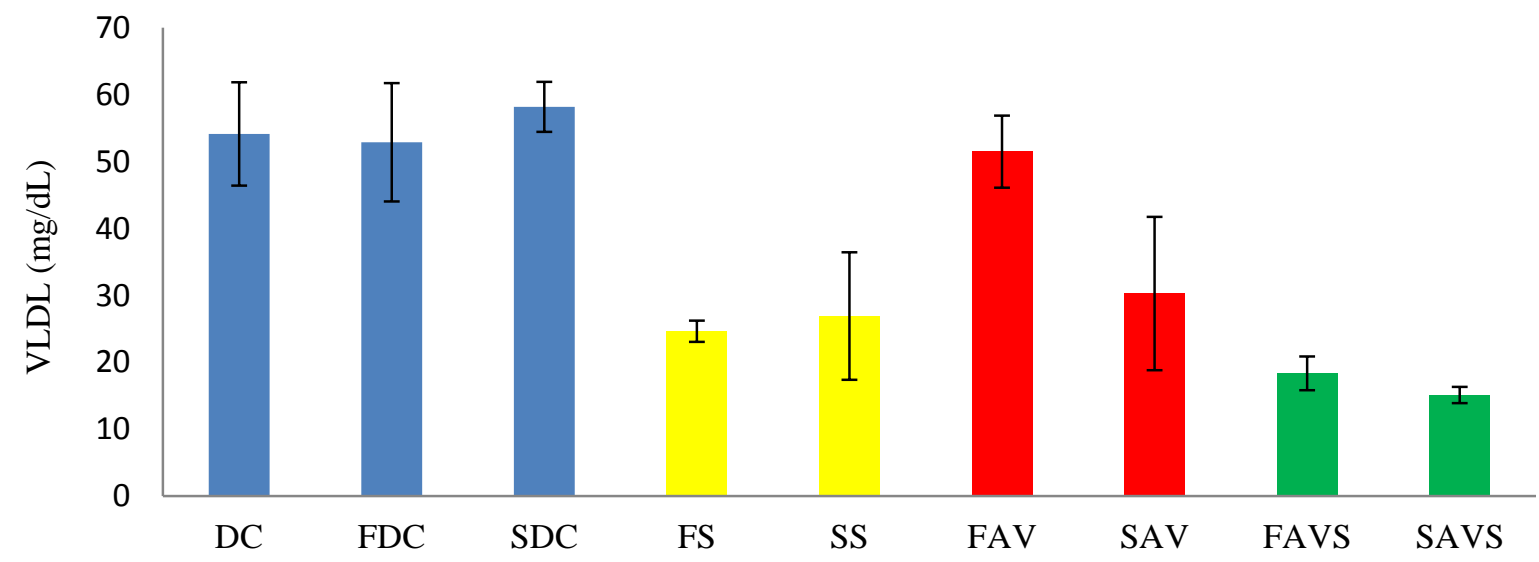

Figure 3. Very low-density lipoprotein levels in diabetic groups of rats. FAV, four weeks of aloe vera consumption; SAV, six weeks of aloe vera consumption; FS, four weeks of swimming; SS, six weeks of swimming; FAVS, four weeks of aloe vera consumption with swimming training; SAVS, six weeks of aloe vera consumption with swimming training; DC, Week-1 diabetic control; FDC, Week-4 diabetic control; and SDC, Week-6 diabetic control

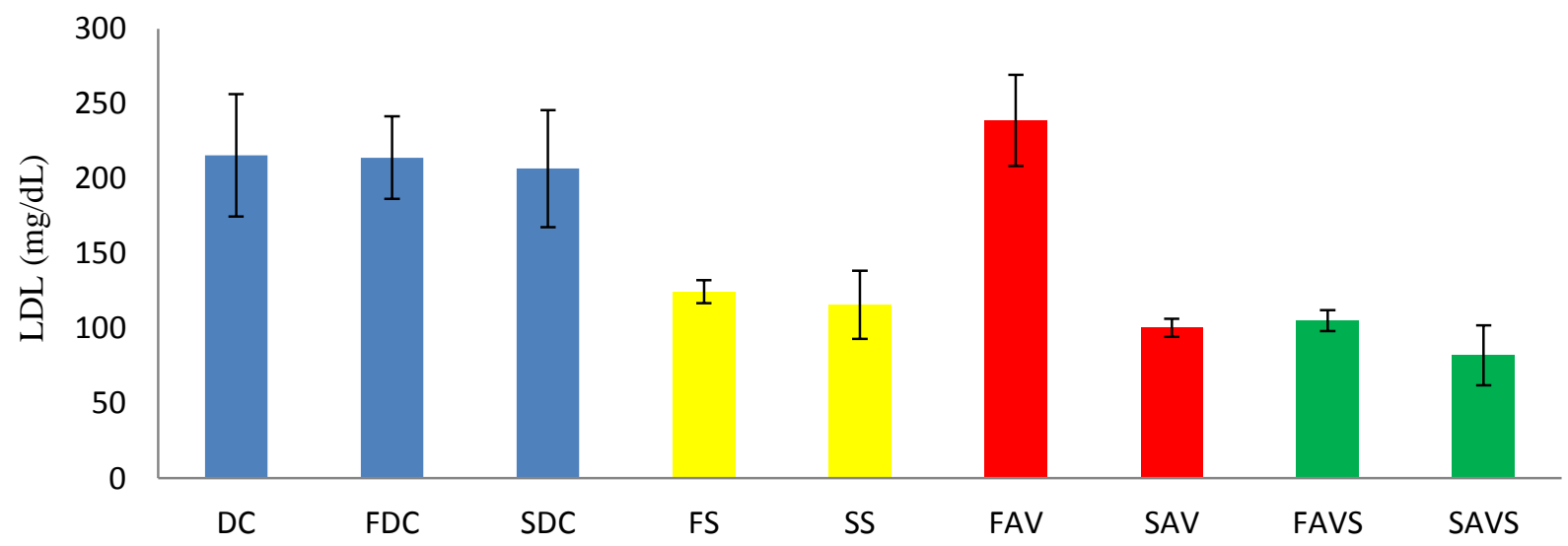

Figure 4. Low-density lipoprotein levels in diabetic groups of rats. FAV, four weeks of aloe vera consumption; SAV, six weeks of aloe vera consumption; FS, four weeks of swimming; SS, six weeks of swimming; FAVS, four weeks of aloe vera consumption with swimming training; SAVS, six weeks of aloe vera consumption with swimming training 
Swimming training included significant effects on HDL increase in diabetic rats $(\mathrm{F}=6.79, P=0.003$, effect size $=0.25$ ); however, use of aloe vera extract did not include significant effects on HDL increase in diabetic rats $(\mathrm{F}=3.10, P=0.06$, effect size $=0.13)$. Swimming training with use of aloe vera extract did not include interactive effects on HDL increase in diabetic rats $(\mathrm{F}=0.12, P=0.88$, effect size $=0.007)$. Results of Bonferroni post-hoc test showed that four weeks of swimming training significantly affected HDL increase in diabetic rats $(P \leq 0.05)$; however, six weeks of swimming training did not significantly affect HDL increase in diabetic rats $(P \geq 0.05)$ (Fig. 5).

\section{Discussion}

In general, results from this study showed that use of aloe vera extract for four weeks did not include significant effects on lipid profiles in diabetic rats. In contrast, use of aloe vera extract for six weeks resulted in significant improvements in lipid profiles in diabetic rats. Studies have shown that use of aloe vera extract decreases TC and TG levels in healthy and diabetic rats $(16,17)$. Use of shorter periods of aloe vera extract includes beneficial effects (10). These results are similar to results from previous studies $(10,16,17)$. The aloe vera extract is likely to normalize distribution of fatty acids (FA) in blood by controlling fat metabolism in the liver. In fact, extract of this plant produces unsaturated fatty acids (UFA) that possibly remove free radicals from the bloodstream and control the metabolism of lipids in the body (10). It has been shown that beta-cystosterol, compostrol and stygomostrel include similarities to phytosterols. Moreover, beta-cystosterol chain in some plants such as aloe vera includes significant decreasing effects on TC, LDL and TG levels by inhibiting the activation of lipid uptake mechanisms (18). Increasing hormone-sensitive lipase activity during insulin secretion deficiency increases release of free fatty acids (FFA) from adipose tissues. Therefore, accumulation of these FAs in the plasma produces further phospholipids and TC in the liver. These two substances enter the blood circulation and increase blood lipoproteins; as TG does. It has been described that aloe vera decreases lipid levels by controlling lipid metabolism in the liver (19). Another mechanism describes that aloe vera extract decreases blood glucose and lipids by increasing cell sensitivity to insulin in diabetic rats (20). However, studies have shown that use of aloe vera extract does not significant affect the lipid profile. In one study, a dose of $50 \mathrm{mg} \mathrm{kg}^{-1}$ did not improve blood TC levels in diabetic rats (21); in contrast to results from the current study. This suggests that the dose required to lower serum TC levels is greater than the highlighted dose.

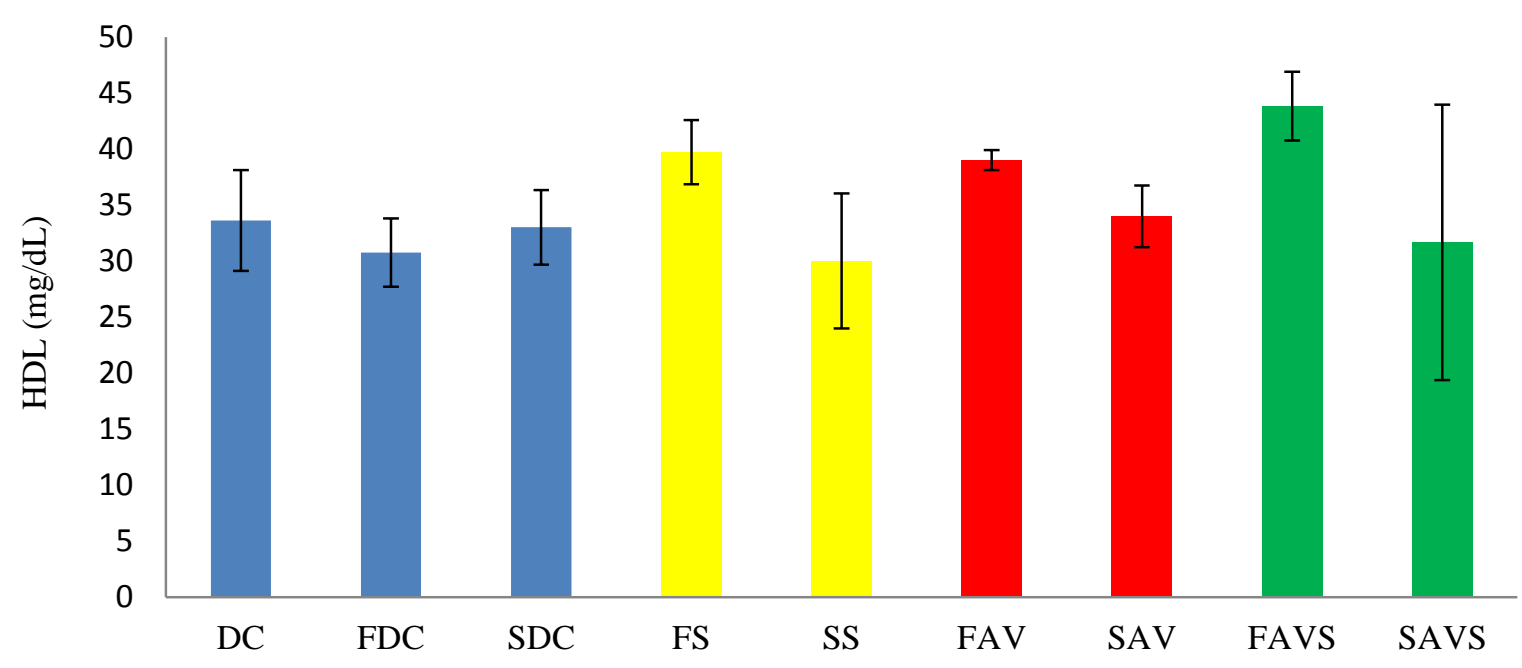

Figure 5. High-density lipoprotein levels in diabetic groups of rats. FAV, four weeks of aloe vera consumption; SAV, six weeks of aloe vera consumption; FS, four weeks of swimming; SS, six weeks of swimming; FAVS, four weeks of aloe vera consumption with swimming training; SAVS, six weeks of aloe vera consumption with swimming training; DC, Week-1 diabetic control; FDC, Week-4 diabetic control; and SDC, Week-6 diabetic control 
Results of this study showed that four and six weeks of swimming training include similar effects on lipid profile improvement in diabetic rats. Dyslipidemia, the most common lipid disorder in type-2 diabetes, includes increased $\mathrm{TG}$ and $\mathrm{TC}$ levels; of which, the latter one is a major risk factor in CVD SINCE Increased TG is associated with increased LDL, which is known as atherogenic factors (22). Dyslipidemia and insulin resistance are associated with increased body fat, especially visceral fats (23). In addition to glycemic control and increased insulin sensitivity (24), exercise can improve CVD risk factors such as visceral fats, lipid profiles, atherosclerosis and endothelial functions (25). Studies on lipid profiles in diabetic patients have been linked to controversial results, some of which changed lipid profiles (26-28) while others did not significantly make changes $(29,30)$ in diabetics following exercises. Based on studies, the optimal reduction in TG and TC in type- 2 diabetic patients is desirably achieved through weight loss. Exercise induced changes in the lipid profile may be independent of body weight (31). Results of the present study have demonstrated that simultaneous use of aloe vera extract and swimming training in diabetic rats interactive decreased lipids. Therefore, it seems that interactions between the aloe vera and the swimming training can be used to improve general conditions of diabetic patients. Swimming training is one of the highlights in this study since this type of exercise can include various responses and adaptations, compared to other exercise programs despite the implementation constraints. However, limitations in the current study included animal specimens. Other limitations of this study included lack of assessments for other CVD risk factors and insulin resistance. Assessment of insulin resistance can help better interpretations of results in diabetics, which is suggested for the future studies.

\section{Conclusion}

Although use of aloe vera extract for four weeks did not include significant effects on lipid profile in diabetic rats, use of aloe vera extract for six weeks resulted in significant improvements in lipid profiles of the animals. Furthermore, four and six weeks of swimming training included similar effects on improvement of lipid profile in diabetic rats. Simultaneous use of aloe vera extract and swimming training in diabetic rats included interactive lipid lowering effects.

\section{Acknowledgement}

The authors express their gratitude for the financial and spiritual supports from the ViceChancellor of Research and Technology of the Islamic Azad University, Marvdasht Branch, and helps from the experts of Sport Physiology Laboratory.

\section{Financial disclosure}

All authors equally contributed to the writing and revision of this manuscript.

\section{References}

1. Howarth F, Marzouqi F, Salem Al Saeedi A, Shaul Hameed R, Adeghate E. The effect of a heavy exercise program on the distribution of pancreatic hormones in the streptozotocininduced diabetic rat. JOP 2009; 10 (5): 485- 491.

2. Ceriello A, Motz E. Is oxidative stress the pathogenic mechanism underlying insulin resistance, diabetes and cardiovascular disease? The common soil hypothesis revisited. Arterioscler Thromb Vasc Biol 2004; 24 (5): $816-823$

3. Soedamah-Muthu SS1, Fuller JH, Mulnier HE, Raleigh VS, Lawrenson RA, Colhoun HM. High risk of cardiovascular disease in patients with type 1 diabetes in the U.K.: a cohort study using the general practice research database. Diabetes Care 2006; 29 (4): 798- 804.

4. Grauslund J, Jorgensen TM, Nybo M, Green A, Rasmussen LM, Sjolie AK. Risk factors for mortality and ischemic heart disease in patients with long-term type 1 diabetes. J Diabetes Complications 2010; 24: 223- 228.

5. Sreelatha S, Inbavalli R. Antioxidant, antihyperglycemic, and antihyperlipidemic effects of coriandrumsativum leaf and stem in alloxan-induced diabetic rats. J Food Sci. 2012; 77(7): 119- 123.

6. Can A, Akev N, Ozsoy N, Bolkent S, Arda BP, Yanardag R, et al. Effect of Aloe vera leaf gel and pulp extracts on the liver in type-II diabetic rat models. Biol Pharm Bull 2004; 27 (5): 694- 698.

7. Parihar M, Chaudhary M, Shetty R, Hemnani T. Susceptibility of hippocampus and cerebral cortex to oxidative damage in streptozotocin treated mice: prevention by extracts of Withania somnifera and Aloe vera. J Clin Neur 2004; 11(4): 397- 402.

8. Rajasekaran S, Aathishsekar D. Therapeutic evaluation of Aloe vera leaf gel extract on glycoprotein components in rats with streptozotocin diabetes. J Pharm Tox 2007; 2(4): 380- 385. 
9. Yeh GY, Eisenberg DM, Kaptchuk TJ, Phillips RS. Systematic review of herbs and dietary supplements for glycemic control in diabetes. Diabetes care 2003; 26 (4): 1277- 1294.

10. Rajasekaran S, Sivagnanam K, Subramanian S. Antioxidant effect of Aloe vera gel extract in streptozotocin-induced diabetes in rats. Pharmacol Rep 2005; 57 (1): 90- 96.

11. Duncan GE, Anton SD. Prescribing exercise at varied levels of intensity and frequency: A randomized trial. Arch Intern Med 2005; 165: 2362- 2366.

12. Tabatabaei SRF, Ghaderi S, Bahrami-Tapehebur M, Farbood Y, Rashno M. Aloe vera gel improves behavioral deficits and oxidative status in streptozotocin-induced diabetic rats. Biomed Pharmacother. 2017; 96:279-290.

13. Ayoubi A, Omidi A, Valizade R, Mousaei A. Effect of hydroalcoholic extract of Aloe vera and Teucrium on serum glucose and lipid profile in streptozotocin diabetic male rats. J Birjand Univ Med Sci 2013; 20 (2): 144- 152.

14. Askari M, Hoseini A. Effect of hydroalcoholic extracts of Anethum graveolens L. with swimming training on lipid profile of diabetic rats. Horizon Med Sci 2016; 22 (4): 345- 351.

15. Zar A, Hoseini A, Ahmadi F, Rezaei M. Effects of ginger together with swimming training on blood fat profiles in adult diabetic rats with streptozotocin. Iranian J Nutr Scie Food Tech 2016; 11 (2): 65- 74.

16. Joshi SC, Gajraj A. Induction of hypocholesterolemia associated with testicular dysfunction by Aloe Barbedensis in Albino Rats. Pharm J 2006; 3: 1 - 8.

17. Kim K, Kim H, Kwon J, Lee S, Kong H, Im S-A, et al. Hypoglycemic and hypolipidemic effects of processed Aloe vera gel in a mouse model of noninsulin-dependent diabetes mellitus. Phyto Med 2009; 16 (9): 856- 863.

18. Kamal-Eldin A, Moazzami A. Plant sterols and stanols as cholesterol-lowering ingredients in functional foods. Rec Pat Food Nutr Agrical 2009; 1 (1): $1-14$.

19. Beppu, Shimpo K, Chihara T, Kaneko T, Tamai I, Yamaji S, Ozaki S, Kuzuya H, Sonoda S. Antidiabetic effects of dietary administration of Aloe Arborescens Miller components on multiple low-dose streptozotocin-Induced diabetes in mice: Investigation on hypoglycemic action and systemic absorption dynamics of Aloe Components. J Ethnopharm 2006; 103 (3): 468- 477.

20. Misawa E, Tanaka M, Nomaguchi K, Nabeshima K, Yamada M, Toida $\mathrm{T}$, et al. Oral ingestion of Aloe vera phytosterols alters hepatic gene expression profiles and ameliorates obesity-associated metabolic disorders in Zucker diabetic fatty rats. J Agricul Food Chem 2012; 60 (11): 2799- 2806.

21. Tanaka M, Misawa E, Ito Y, Habara N, Nomaguchi $\mathrm{K}$, Yamada $\mathrm{M}$, et al. Identification of five phytosterols from Aloe vera gel as anti-diabetic compounds. Biol Pharma Bull 2006; 29 (7): 14181422 .

22. Manjunath CN, Rawal JR, Mehelli Irani P, Madhu K. Atherogenic dyslipidemia. Indian $\mathrm{J}$ Endocrinol Metab. 2013; 17(6): 969-976.

23. Castro AV, Kolka CM, Kim SP, Bergman RN. Obesity, insulin resistance and comorbidities? Mechanisms of association. Arq Bras Endocrinol Metabol. 2014;58(6):600-9.

24. Park JH, Lee YE. Effects of exercise on glycemic control in type 2 diabetes mellitus in Koreans: the fifth Korea National Health and Nutrition Examination Survey (KNHANES V). J Phys Ther Sci. 2015; 27(11): 3559-3564.

25. Pedralli ML, Waclawovsky G, Camacho A, Markoski MM, Castro I, Lehnen AM. Study of endothelial function response to exercise training in hypertensive individuals (SEFRET): study protocol for a randomized controlled trial. Trials. 2016 Feb 13; $17: 84$.

26. Kang S, Woo JH, Shin KO, Kim D, Lee H-J, Kim YJ, et al. Circuit resistance exercise improves glycemic control and adipokines in females with type 2 diabetes mellitus. J Sports Sci Med 2009; 8: 682- 688.

27. Terada T, Friesen A, Chahal B S, Bell GJ, McCargar LJ, Boulé NG. Feasibility and preliminary efficacy of high intensity interval training in type 2 diabetes. Diabetes Res Clin Pract 2013; 99: 120- 129.

28. Aggarwala J, Sharma S, Jain A, Sarkar A. Effects of aerobic exercise on blood glucose levels and lipid profile in Diabetes Mellitus type 2 subjects. Al Ameen J Med Sci 2016; 9(1): 65- 69.

29. Khademosharie M, Amiri Parsa T, Hamedinia M R, Azarnive M A, Hosseini-Kakhk S A R. Effects of two aerobic training protocols on Vaspin, Chemerin and lipid profile in women with type 2 diabetes. Iran South Med J 2014; 17 (4): 571- 581.

30. Mokhtari F, Esfarjani F, Kargar Fard M. The effect of combined aerobic exercise and barley b-glucan on lipid profile and glucose blood of women with diabetes type two. IJDLD 2014; 13 (4): 340- 351.

31. Yavari A, Najafipoor F, Aliasgarzadeh A, Niafar M, Mobasseri M. Effect of aerobic exercise, resistance training or combined training on glycaemic control and cardiovascular risk factors in patients with type 2 diabetes. Biol Sport 2012; 29: 135- 143. 